\title{
Editorial
}

\section{Medical waste management}

Jean Bosco Gahutu, Editor in Chief

"Above all do no harm" is a fundamental principle of medical practice. Obligation for health facilities and health professionals to do no harm is valid for the protection of the patients, the visitors, including patient family members, and the hospital staff. The hospital environment must be free of any hazard that can endanger the safety of patients, visitors or health professionals. For that purpose, emphasis is put on medical waste management.

Indeed, if inappropriately managed, hospital waste can constitute a danger to the health of patients, visitors and hospital staff. The nature of the hazard may be chemical, physical or microbiological among others. This is why medical waste management is of utmost importance to ensure a healthy environment in the hospital, thereby ensuring occupational health to the clinical and other hospital staff in addition to the protection of patients and visitors.

Quality improvement programmes are ongoing at Rwandan hospitals, aiming at meeting the requirements for accreditation; they include medical waste management.

The responsibility for medical waste management is collective, involving hospital management, clinical, allied and administrative staff and private companies in charge of cleaning and hygiene.

Proper management of hospital waste is of utmost importance for occupational health and safety.[1] Ensuring occupational health with regards to medical waste management involves several steps: protection of the hospital and cleaning staff in charge of waste disposal, which includes availing adequate equipment and materials for waste processing, transport and disposal. Protection must also be ensured for the hospital staff, patients and visitors in the vicinity of the area where the hospital waste is stored before disposal.

Equally important is the availability of materials for waste segregation, including colour-coded dustbins. Equipment and materials for waste disposal is important, including facilities for incineration.

Education of hospital staff and the staff of contractual companies in charge of cleaning and hygiene is crucial for them to have appropriate knowledge and attitudes and adequate skills in hospital waste management.[2] Relevant policies and guidelines are indispensable for effective hospital waste management.[3]

The article by Karenzi and collaborators published in this issue reports findings of a study on occupational health risks associated with medical waste management practices among health professionals working in three district hospitals in Rwanda. The results show that much effort is needed to raise the standards of medical waste management.

\section{References}

1. Manyele S V., Tanzania V. Effects of improper hospital-waste management on occupational health and safety. African Newsl Occup Heal Saf [Internet]. 2004;14:30-33. Available from: http://www.bvsde.ops-oms.org/ bvsacd/cd46/effects.pdf

2. Sahiledengle B. Self-reported healthcare waste segregation practice and its correlate among healthcare workers in hospitals of Southeast Ethiopia. BMC Health Serv Res. BMC Health Services Research; 2019;19:1-11.

3. Awodele O, Adewoye AA, Oparah AC. Assessment of medical waste management in seven hospitals in Lagos, Nigeria. BMC Public Health [Internet]. BMC Public Health; 2016;16:1-11. Available from: http://dx.doi.org/10.1186/s12889-016-2916-1

Rwanda J Med Health Sci 2019;2(3):212. 